\title{
Using Gis System In Assessing Real Estate Property
}

\author{
Voichiţa ROIB ${ }^{1 *}$, Ilinca ROIB ${ }^{2)}$ \\ 1) Faculty of Civil Engineering, Technical University of Cluj-Napoca, 15 C-tin Daicoviciu, 400020 Cluj- \\ Napoca, Romania \\ 2) Faculty of Geography, Babeş-Bolyai University, 1 Kogălniceanu, Cluj-Napoca, Romania. \\ ${ }^{*}$ Corresponding author, e-mail: Voichita.Roib@infra.utcluj.ro
}

Bulletin UASVM Horticulture 71(2) / 2014

Print ISSN 1843-5254, Electronic ISSN 1843-5394

DOI:10.15835/buasvmcn-hort:10654

\begin{abstract}
Geographic Information System (GIS) represents a technology used in different domains of activity, being used for centralizing and accessing information. GIS system may be used in assessing real estate property. With regard to assessing real estate properties, the GIS platforms can be useful for offering tools for special spatial analysis in order to learn the real space, with the help of which data is collected, managed, manipulated, analyzed and displayed in order to obtain a reasonable assessment of the value of a real estate property. Due to GIS the assessor can understand, interpret and share data in many ways. The GIS data base helps the assessor understand the general and physical characteristics of the property in a fast and easily comprehendible way. The assessment process consists of a set of coherent and organized procedures applied by the assessor, which lead to the value estimation of a real estate property. The authors of the study have created a GIS data base for managing the necessary data for property evaluation. The properties consists of houses in a row and the land belonging to them, located in the western area of Cluj-Napoca municipality, in Gheorgheni District. Due to the created GIS data base one can analyze the physical characteristics of the buildings, necessary to value estimation and to identify and select reliable comparables.
\end{abstract}

Keywords: GIS, real estate property

Introduction. GIS represents an information tool used for mappingand analyzing existing objects and events that take place on Earth, it integrates operations with data bases like interrogations and statistical analysis, with the advantage of unique visualization and geographical analysis offered by maps. The present research work, presents the using of a GIS data base in assessing real estate property.

Aims and objectives. By using the GIS platform one can create a database with relevant information on specific general characteristics, design and spatial parameters of the property, with the help of which a useful analysis can be made in the process of assessing real estate property.

Materials and methods. During the process of assessing, the assessor has to describe the physical characteristics of a property and to analyze them, in order to create the necessary basis for comparing the subject property to the properties considered to be typical on the market of the subject property, and comparing it to the ones determined after the analysis of the best use. The GIS data entered into the data base is relatively correct, however this process is not meant to substitute the assessing process. This matter is important for undeveloped, developed and excess land, as well. Due to the analysis of a highly defined satellite image together with the GIS visual data of the property, the assessor can determine the size of the land parcels, this being very important in the process of comparing the properties with the unit price of the land. The geographic information system facilitates additional geographic reference data for individual elements held in the real estate properties data base. Due to this information, the relation between two known points in space can be displayed. This way the assessor can organize the information and create its image of distribution in space, following its analysis. GIS 


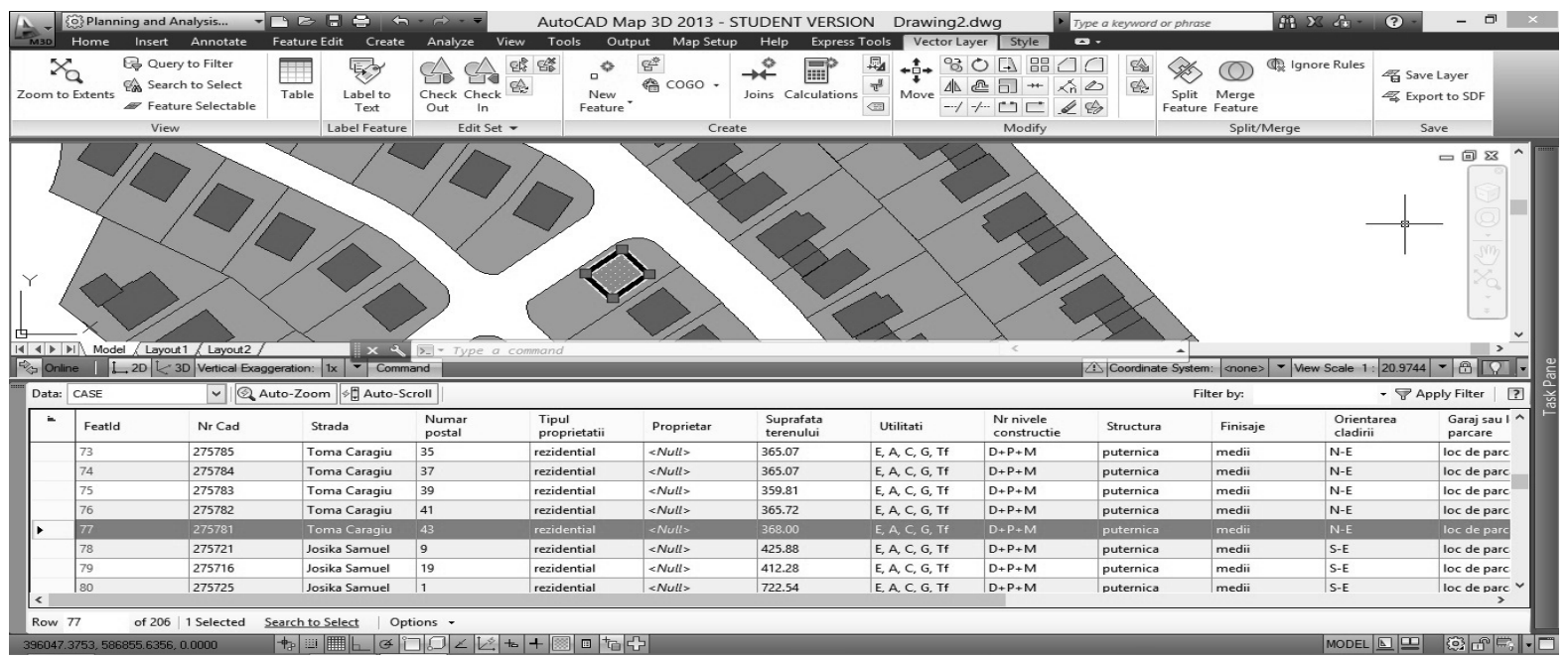

Fig. 1. Display of related data from the data base

facilitates the graphic display of geocoded data and the analysis of physical characteristics and of geographic relations on a market area (Appraisal Institute, 2011).

The AutoCAD Map 3D program was used in order to create the data bases. This includes CAD (Computer Aided Design) functions, as well as GIS-type functions; thus, being in the same work medium, the processes of design and management are a lot easier and coherent. During the assessment of the real estate property the assessor has to describe and analyze the location. The description consists of concrete and comprehensive data, information on usage restrictions of the land, an official description, other titles and information about physical characteristics. Due to the GIS data basis one can analyze: the size and shape of the location, the influence of corners, re-parcelling, surplus land, topography, utilities, site preparation, access possibilities and environment (Roib, 2012).

Results and Discussion. A very important stage for estimating the value of a property is: the description of type, structure, quality and condition of the buildings situated on the location. Due to the created GIS data base, the following details of the existing buildings can be analyzed: structural components, materials and installations, details on finishes, facilities, size, condition of each described element, and the current usage of the property. The GIS data base allow the view of the buildings situated on the location, checking the data base, display of related data from the data base, management of data from the database (Fig.1). The GIS data base leads to a better understanding of current market conditions, developing trends, and individual components of value for each property type.

Conclusion. In the present paper, the authors present a GIS data base for managing the necessary data for property evaluation. The GIS data base offers a useful tool for value estimation in data management concerning real estate properties and helps with providing supplementary data about the characteristics of the property. The assessor can organize the information about the properties and create its image of distribution in space, following its analysis. GIS facilitates the graphic display of geocoded data and the analysis of physical characteristics and of geographic relations on a market area.

\section{REFERENCES}

1. Appraisal Institute, (2011). Evaluarea proprietăţii imobiliare, ediţia a 13-a, Ediţia în limba româna, Bucureşti.

2. Roib V (2012). Evaluarea bunurilor imobile - Noțiuni generale privind drepturi asupra proprietății imobiliare, Editura UTPRESS, Cluj-Napoca.

3. Tomlinson R (2007), Thinking about GIS, Esri Pr. 